Check for updates

Cite this: RSC Adv., 2017, 7, 47083

Received 24th August 2017

DOI: $10.1039 / \mathrm{c} 7 \mathrm{ra09377b}$

rsc.li/rsc-advances
Accepted 24th September 2017

\section{Removal of dye molecules from aqueous solution by carbon nanotubes and carbon nanotube functional groups: critical review}

\begin{abstract}
M. Rajabi, ${ }^{a}$ K. Mahanpoor ${ }^{a}$ and O. Moradi iD *b
For the removal and separation of wastewater pollutants, one widely used technique is adsorption. Different materials have been used as adsorbents. Among several adsorbents, carbon nanotubes (CNTs) are emerging as potential adsorbents because of their large surface area, defined cylindrical hollow structure, high ratio aspect, easy modification and hydrophobic wall surfaces. In this review, the capability of adsorption of dyes on CNTs and functionalized CNTs has been compiled. This paper provides data about defects, adsorption sites on CNTs and adsorption process studies under the effect of such various operational parameters as solution $\mathrm{pH}$, contact time, and temperature, and deals with the mechanisms involved in the adsorption of dyes onto CNTs. According to observations from the articles reviewed, functionalized carbon nanotubes have better sorption capacity than as-grown CNTs. For the removal of dyes from aqueous solution, carbon nanotubes (CNTs) have shown good potential and some of the functional groups improve the adsorption potential according to evidence from the literature. For example, the maximum adsorption amount $\left(q_{\max }\right)$ of methylene blue dye on an MWCNT surface has been reported to be $100 \mathrm{mg} \mathrm{g}^{-1}$ while the maximum adsorption amount of methylene blue dye on functionalized MWCNT-SH surface was $166.7 \mathrm{mg} \mathrm{g}^{-1}$. This indicates that functionalization is beneficial in increasing the amounts of absorption. However, the development of highly efficient, cost effective environmentally friendly CNT-based nano adsorbents for their commercial applications should be the focus of still more study.
\end{abstract}

\section{Introduction}

Pollution of ground and running waters by industrial dyes is a threat to aquatic life and human beings and is a main environmental problem. ${ }^{\mathbf{1 - 4}}$ Synthetic dye stuffs are extensively used as coloring agents in the paper, textile, gasoline, food, and pharmaceutical industries. The hydrosphere contaminated by the discharge of dyes into the environment is a notable source of pollution due to its recalcitrant nature, visibility even at very low concentrations, giving an undesirable color to the water, biological attack, and reducing sunlight penetration..$^{5-10}$ The aromatic molecular structure of dyes presumably comes from coal tar-based hydrocarbons such as naphthalene, benzene, toluene, and xylene. ${ }^{11,12}$ Today, the yearly production of commercial dyes is $>7 \times 10^{5}$ tons per year, and to date, more than 100000 dyes are known. ${ }^{12-16}$ Therefore, a significant area of applied and basic research deals with the removal of dye pollution from industrial wastewater. ${ }^{17,18}$

${ }^{a}$ Department of Chemistry, Faculty of Science, Arak Branch Islamic Azad University, Arak, Iran

${ }^{b}$ Department of Chemistry, Shahre-Qods Branch, Islamic Azad University, ShahreQods, Tehran, Iran.E-mail:moradi.omid@gmail.com; o.moradi@qodsiau.ac.ir
To remove dyes from wastewater, some methods such as ozonation, flocculation, membrane separation, aerobic or anaerobic treatment, coagulation and adsorption are used by industry. ${ }^{19}$ Nevertheless, adsorption is one method which has been most widely used because it is inexpensive, and easy and impressive for dye removal from industrial wastewater. Various adsorbents are used in adsorption processes such as activated carbon, ${ }^{\mathbf{2 0}-25}$ graphene nanosheets, multi-walled carbon nanotubes, cedar sawdust, crushed brick, magnetic chitosan/ grapheme, and oxide composites. ${ }^{\mathbf{2 6 - 3 5}}$ To remove dyes from aqueous solutions, activated carbon is one of the best adsorbents. ${ }^{36-40}$ Because of their large surface area and high porosity, activated carbons have high adsorption capacity. But the low regeneration and high cost of activated carbon restrict its use. ${ }^{\mathbf{4 1}}$ Different studies have shown the adsorption ability of dyes on a large variety of non-conventional low-cost adsorbents, such as agricultural and industrial waste. ${ }^{41-53}$ Nonetheless, in very few cases, for non-conventional adsorbents and low-cost adsorbents, is the adsorption capacity higher than for activated carbons and these adsorbents showed mixed results. So, to develop more efficient adsorbents with a higher capacity for regeneration, the study of nanotubes is an ongoing process. One carbon allotrope is carbon nanotubes (CNTs, 1D) consisting of $\mathrm{sp}^{2}$-hybridized carbons, ${ }^{54}$ graphene $(2 \mathrm{D}),{ }^{53,54}$ as well as 
graphite (3D). ${ }^{55}$ Since CNTs were discovered in 1991 by Iijima, ${ }^{56}$ a variety of them have become available, such as single, double, few, and multi-walled carbon nanotubes. ${ }^{57-60}$ Carbon nanotubes (CNTs) have been intensively studied as a potential material to be used in a variety of applications based on their unusual chemical and physical properties. ${ }^{61}$ Compared with adsorbents such as clay and activated carbon, CNTs are more attractive because of their high selectivity, structural diversity and favorable physicochemical stability. ${ }^{62}$

In this paper, the adsorption capacities of dyes on carbon nanotubes and functionalized carbon nanotubes are reviewed. The results of recent research are used to compare the usage of carbon nanotubes and functionalized carbon nanotubes as the basis of adsorbents for the removal of dyes. The effect of various parameters such as experimental conditions (i.e. solution $\mathrm{pH}$, contact time, initial concentration, and temperature), dyes, and adsorbent characteristics on the adsorption capacity are discussed and presented. Also, in this paper thermodynamic, kinetic, and adsorption isotherm studies are reviewed.

\section{Dye classification}

There are many ways to classify dyes in terms of method of application, colour, and structure. ${ }^{63}$ But the application classification is often favourable due to the extent and complexity of the nomenclature of colour from the system of chemical structure. ${ }^{64}$ Table 1 presents the usual classes of dye classification according to the chemical structure of the dyes. Table 2 shows the classification according to the application of the dyes. Dyes are usually categorized according to the charge of the particle upon dissolution in aqueous solution ${ }^{65}$ such as anionic (acid, reactive, and direct dyes), cationic (all basic dyes), and non-ionic (dispersed dyes).

Several industries such as the paper, dye stuff, plastic, printing, textile, carpet, cosmetics, and food, use dyes in their products to provide colour. These dyes are always left over in industry and the waste is usually discharged into the environment. ${ }^{66,67}$

\subsection{Dye toxicity}

Dyes have great colour intensity and are easily visible even in very low concentrations. ${ }^{68}$ Complex dyes are generally based on chromium, which is carcinogenic. ${ }^{69}$ There are many aromatic structures in dye compounds that form stable complexes, which are resistant against heat, optical oxidizing agents, and biodegradation. ${ }^{70}$ Because of the presence of toxic amines in the effluent, azo dyes are classified as toxic. ${ }^{71,72}$ Degradation-based dyes are highly sustainable and have higher longevity in effluents. ${ }^{72}$ In the environment, reactive dyes cause serious trouble because they are soluble in water and give a highly coloured effluent. ${ }^{73}$ Also, having low biodegradability and being chemically stable, reactive dyes are likely to pass through conventional treatment plants, so their elimination is of high importance. ${ }^{74}$ Dyes affect the photosynthetic activity of aquatic life as they decrease the penetration of light and are replete with metals, and aromatics, which may be toxic to some aquatic life.$^{75}$ Also, dyes are carcinogenic, teratogenic, or mutagenic in different microbiological species of fish. Additionally, they can severely damage human beings through dysfunction of the reproductive system, kidneys, central nervous system, brain, and liver. ${ }^{76}$

\section{Dye adsorption process on CNTs}

The active sites and defects of the CNT surface play an important role in dye adsorption on CNTs. CNTs consist of graphene or graphitic sheets, which have been rolled up into a cylindrical shape and exhibit a special sidewall curvature, and possess a $\pi$ conjugative structure with a highly hydrophobic surface. CNTs are called single-walled carbon nanotubes (SWCNTs) when they have one graphitic shell and multi-walled carbon nanotubes (MWCNTs) when they have several concentric graphitic shells. The main mechanisms of absorbing different dye compounds by CNTs depend on whether the dyes are cationic or anionic. In most cases, the adsorption prediction of dyes on carbon nanotubes may not be simple, ${ }^{77}$ and different possible interactions between carbon nanotubes and dyes have been proposed. Hydrophobic, van der Waals forces, $\pi-\pi$ stacking, hydrogen bonding, and electrostatic interactions might act simultaneously or individually. ${ }^{78}$

\subsection{Effective factors in dye adsorption on CNTs}

Many factors are involved in dye adsorption by carbon nanotubes, such as initial concentration of dye, solution $\mathrm{pH}$, temperature, and dosage of carbon nanotubes. To remove dyes in order to optimize industrial-scale development processes, an in-depth study of these parameters will be of great help. So, these factors are discussed here. ${ }^{7-81}$

3.1.1. Initial concentration of dye. The initial concentration of dye has a great effect on the removal of the dye. The initial dye concentration effect relies on the immediate relationship between the sites available for binding on the surface of the adsorbent and the concentration of the dye. As the initial concentration of the dye increases, the efficiency of dye removal decreases according to the saturation of adsorption sites on the surface of the adsorbent. ${ }^{82}$ At a low concentration of dye, there will be unoccupied binding sites on the surface of the adsorbent and when the initial concentration of dye increases, there will be insufficient sites for the dye molecules to adsorb: therefore, the efficiency of dye removal decreases. ${ }^{83}$

3.1.2. The effect of solution pH. Many articles have investigated the effect of solution acidity on the removal of the dye by CNTs from aqueous solution, and in several studies on dye adsorption it was reported that the acidity effect is one of the most important factors affecting dye removal through carbon nanotubes. Therefore, the solution $\mathrm{pH}$ is an effective parameter in dye removal. For example, Seow and Lim in a review article expressed that whereas for adsorption of cationic dye a high value of solution $\mathrm{pH}$ was preferred, a low value of solution $\mathrm{pH}$ is more suitable for the adsorption of anionic dye. ${ }^{84}$

3.1.3. Temperature. One important factor affecting the dye adsorption on carbon nanotubes is temperature. Adsorption is 
Table 1 Dye classification based on the chemical structure the dye comes from ${ }^{63}$

Nitro dyes

Indigoid dyes

Fast Yellow AB

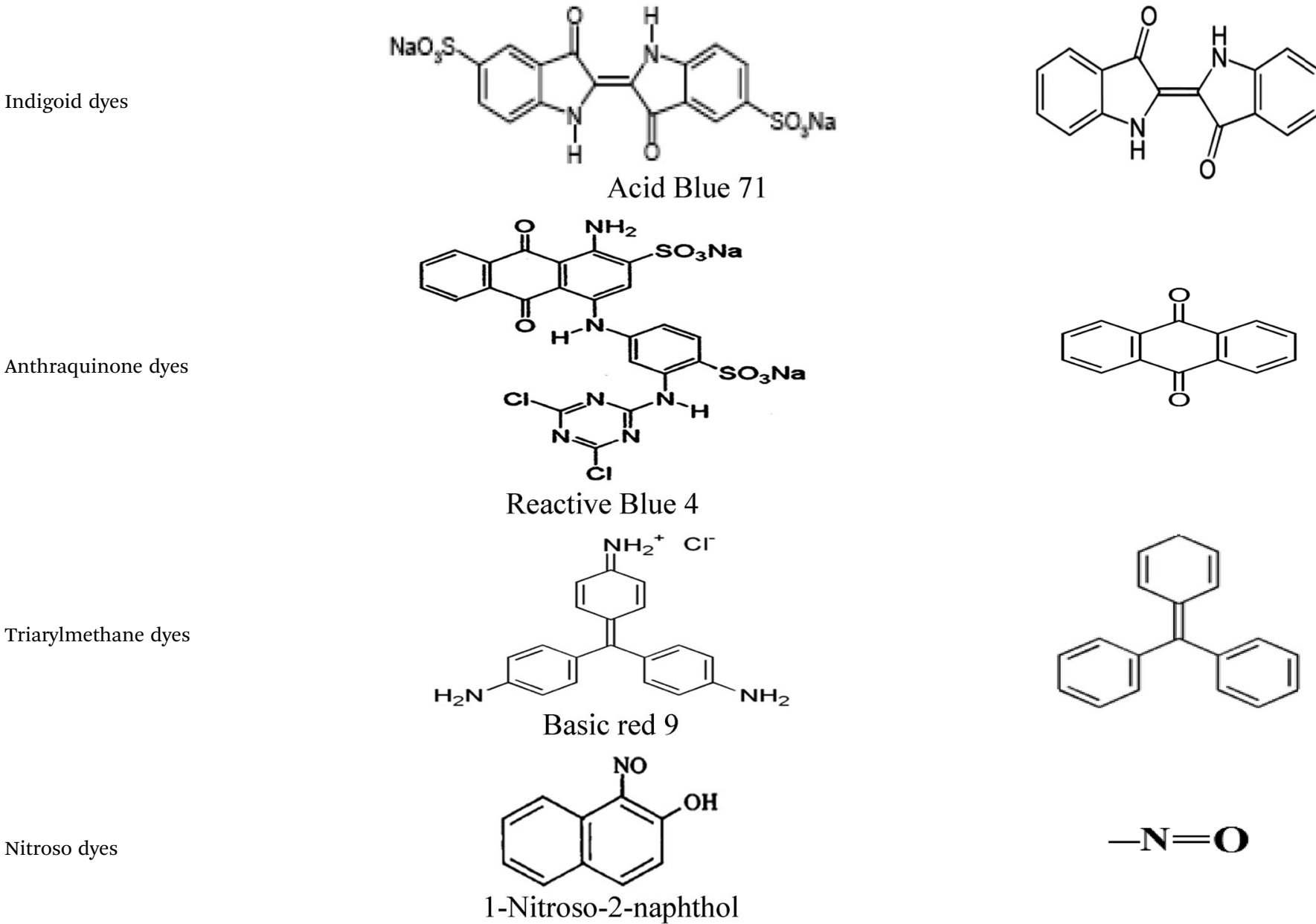

a process which can be endothermic or exothermic for different adsorbents and dyes. If increasing temperature decreases the removal efficiency of the dye, dye adsorption on carbon nanotubes will be endothermic, and if increasing temperature decreases the removal efficiency of the dye, dye adsorption on carbon nanotubes will be exothermic. ${ }^{85}$ For example, Kuo et al. examined some dye adsorption on carbon nanotubes and found that the removal of Direct Yellow 86 (DY86) dye by a carbon nanotubes surface is endothermic, ${ }^{86}$ as they observed that the adsorption capacity decreased slightly with an increase in temperature. Konicki et al. studied adsorption of Acid Red 88 (AR88) dye on a magnetic multi-walled carbon nanotubes- $\mathrm{Fe}_{3} \mathrm{C}$ nanocomposite and found that removal of Acid Red 88 dye is exothermic. ${ }^{87}$ Also, Yao et al. studied methylene blue adsorption on carbon nanotubes and found that removal of methylene blue dye was endothermic. ${ }^{88}$ 
Table 2 Dye classification according to their chemical nature (adopted from ${ }^{64}$ )

\begin{tabular}{|c|c|c|c|}
\hline Class & Method of application & Substrate & Chemical types \\
\hline Direct & $\begin{array}{l}\text { Used from slightly alkaline or } \\
\text { neutral baths containing additional } \\
\text { electrolyte. }\end{array}$ & $\begin{array}{l}\text { Rayon, nylon, leather, paper, and } \\
\text { cotton. }\end{array}$ & $\begin{array}{l}\text { Azo, oxazine, phthalocyanine, } \\
\text { stilbene. }\end{array}$ \\
\hline Basic & Used from acidic dye baths. & $\begin{array}{l}\text { Paper, inks, polyacrylonitrile, } \\
\text { polyester, and treated nylon. }\end{array}$ & $\begin{array}{l}\text { Azo, diazahemicyanine, cyanine, } \\
\text { xanthene, acridine, triarylmethane, } \\
\text { oxazine, azine diphenylmethane, } \\
\text { and anthraquinone. }\end{array}$ \\
\hline Dispersed & $\begin{array}{l}\text { Often applied by lower fine aqueous } \\
\text { dispersions temperature or high }\end{array}$ & $\begin{array}{l}\text { Acrylic polyester, polyamide, } \\
\text { plastics, and acetate. }\end{array}$ & $\begin{array}{l}\text { Azo, benzodifuranone, nitro, styryl, } \\
\text { and anthraquinone. }\end{array}$ \\
\hline
\end{tabular}

Reactive Reactive site on dye reacts with pressure/temperature method carrier; dye may be padded on thermo and fixed cloth. functional group on fibre to bind dye covalently under influence of $\mathrm{pH}$ and heat.

Sulfur $\quad$ Aromatic vatted substrate with reoxidized sodium sulfide and to form insoluble sulfur-containing products on fibre. plastics, and acetate.

Nylon, cotton, wool, and silk.

Cotton and rayon.
Azo, phthalocyanine, anthraquinone, basic, and formazan, oxazine.

Structures indeterminate.

\subsection{Isotherm of dye adsorption on CNTs}

To study the dye adsorption isotherm on CNTs, it is necessary to measure the relationship between the equilibrium pressure, the amounts adsorbed, $n_{\mathrm{a}}$, and $P$ at constant temperature: ${ }^{88}$

$$
n_{\mathrm{a}}=F(P)_{\mathrm{T}}
$$

3.2.1. Chemical and physical adsorption. The process of dye adsorption is normally considered to be a physical process in which van der Waals power in the adsorption process is usually dominant. ${ }^{\mathbf{8 9 - 9 4}}$ The adsorption of physical liquid on solid surfaces occurs in an adsorption process during electron

Table 3 A comparison of the adsorption capacities of various adsorbents for some cationic dyes

\begin{tabular}{|c|c|c|c|c|c|c|}
\hline Adsorbent & Dye & $q\left(\mathrm{mg} \mathrm{g}^{-1}\right)$ & Time & Temperature (K) & $\mathrm{pH}$ & Ref. \\
\hline MWCNTs & Malachite green & 142.85 & $80(\mathrm{~min})$ & 298 & 7 & 98 \\
\hline CNT/polyaniline composites & Malachite green & 13.95 & $10(\min )$ & 293 & 7 & 99 \\
\hline SWCNT & Malachite green & 4.9285 & $15(\min )$ & 300 & 7 & 101 \\
\hline SWCNT-NH ${ }_{2}$ & Malachite green & 6.1340 & $15(\min )$ & 300 & 7 & 101 \\
\hline SWCNT-COOH & Malachite green & 19.841 & $15(\min )$ & 300 & 7 & 101 \\
\hline MWCNT-COOH & Malachite green & 11.63 & $10(\min )$ & 328 & 9 & 44 \\
\hline MWCNT-SH & Methylene blue & 166.7 & $60(\min )$ & 298 & 6 & 82 \\
\hline MWCNT & Methylene blue & 100 & $60(\min )$ & 298 & 6 & 82 \\
\hline Carbon nanotubes & Methylene blue & 35.4 & $45(\min )$ & 273 & 7 & 88 \\
\hline Carbon nanotubes & Methylene blue & 46.2 & $45(\mathrm{~min})$ & 298 & 7 & 88 \\
\hline Carbon nanotubes & Methylene blue & 64.7 & $45(\min )$ & 333 & 7 & 88 \\
\hline Composite of graphene-CNT & Methylene blue & 65.79 & $30(\mathrm{~min})$ & 283 & 7 & 104 \\
\hline SWCNT & Basic red 46 & 38.35 & $100(\min )$ & 298 & 9 & 105 \\
\hline SWCNT & Basic red 46 & 33.12 & $100(\mathrm{~min})$ & 308 & 9 & 105 \\
\hline SWCNT-COOH & Basic red 46 & 49.45 & $100(\mathrm{~min})$ & 298 & 9 & 105 \\
\hline SWCNT-COOH & Basic red 46 & 45.33 & $100(\min )$ & 308 & 9 & 105 \\
\hline MWCNT & Maxilon blue & 187.69 & $120(\mathrm{~min})$ & 303 & 10 & 106 \\
\hline
\end{tabular}


exchange between the molecules of dyes into the solution phase and the carbon nanotubes surface, and chemical bond formation is not necessary. ${ }^{93-95}$ Unlike physical adsorption, for the molecular forces during the process of adsorption, an electron exchange reaction means that a chemical adsorption occurs between the dye molecules of the solution and the solid surface of the carbon nanotubes. ${ }^{\mathbf{9 4 , 9 5}}$

3.2.2. Monolayers and multilayers. For open surfaces, adsorption consists of a layer-by-layer loading process, where the first layer is filled as $\theta=n_{\mathrm{a}} / N_{\mathrm{m}}=1$, where $\theta$ is the recovery of the surface, and $N_{\mathrm{m}}$ is the capacity of the monolayer. According to the result, it is understood that when $\theta=n_{\mathrm{a}} / N_{\mathrm{m}}<1$, we have monolayer adsorption, and when $\theta=n_{\mathrm{a}} / N_{\mathrm{m}}>1$, the adsorption is multilayer.

To optimize the adsorption system design for the dye adsorption process, it is important to establish the most appropriate correlation for the curves of equilibrium. Various isotherm equations have been used to describe the dye adsorption equilibrium on the carbon nanotubes surface. Some of these isotherms are Langmuir and Freundlich. The Langmuir isotherm model is one of the most widely used. It is observed that the Langmuir isotherm model can be linearized in at least four different types. The Langmuir isotherm model can be expressed as: ${ }^{\mathbf{9 6}, 97,103}$

$$
\text { Type }(\mathrm{I}): \frac{C_{\mathrm{e}}}{q_{\mathrm{e}}}=\frac{1}{K Q_{\mathrm{m}}}+\frac{C_{\mathrm{e}}}{Q_{\mathrm{m}}}
$$

$$
\begin{aligned}
& \text { Type (II): } \frac{1}{q_{\mathrm{e}}}=\frac{1}{Q_{\mathrm{m}}}+\frac{1}{K Q_{\mathrm{m}} C_{\mathrm{e}}} \\
& \text { Type (III): } q_{\mathrm{e}}=Q_{\mathrm{m}}-\frac{q_{\mathrm{e}}}{K C_{\mathrm{e}}} \\
& \text { Type (IV): } \frac{q_{\mathrm{e}}}{C_{\mathrm{e}}}=K Q_{\mathrm{m}}-K q_{\mathrm{e}}
\end{aligned}
$$

where $Q_{\mathrm{m}}\left(\mathrm{mg} \mathrm{g}^{-1}\right)$ and $K\left(\mathrm{~L} \mathrm{mg}^{-1}\right)$ are Langmuir constants corresponding to dye removal capacity and adsorption energy.

3.2.3. Carbon nanotubes properties. The discovery of carbon nanotubes was very important. Because of their seamless graphite structure, and being nearly cylindrical, they have attracted much attention. Their thermal, mechanical, electrical, and physical properties make them ideal for work on SWNT and MWNT. Because of their high efficiency, the process of production of carbon nanotubes has progressed rapidly. In dye adsorption on carbon nanotubes, these properties have been taken into account because the surface area to volume ratio in CNTs is greater than in other common adsorbents. So, the chemical reaction with dye molecules for CNTs is more effective than for other common adsorbents which leads to the high contact surface of the effective collisions between the molecules of the dyes and the surface of the carbon nanotubes which in turn leads to an improvement in the efficiency of the adsorbent. ${ }^{124-128}$ Tables 3 and 4 .

Table 4 A comparison of the adsorption capacities of various adsorbents for some anionic dyes

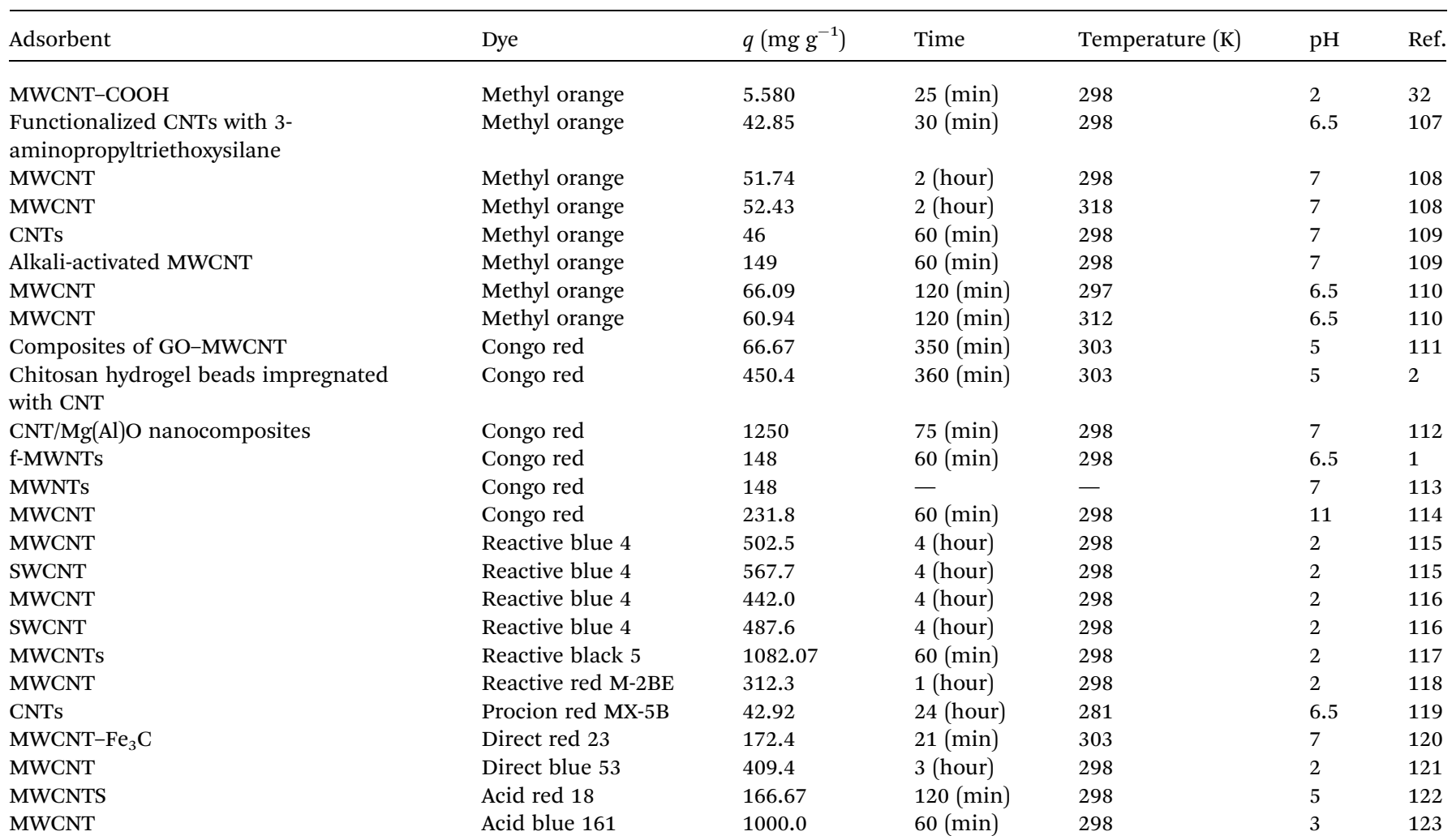




\section{Conclusion}

In recent years, many papers have been published on dye adsorption. In this review, the adsorption potential of carbon nanotubes and functionalized carbon nanotubes in the removal of dye molecules from wastewater has been highlighted. This paper presented dye classification according to their chemical nature and based on the dyes' chemical structure, and discussed dye toxicity. It also presented the effect of different chemical and physical conditions of adsorption on the adsorption capacity of dyes on carbon nanotubes and functionalized carbon nanotubes, such as initial concentration of dye, solution $\mathrm{pH}$, and temperature. The $\mathrm{pH}$ of the solution is one of the main parameters in the adsorption of cationic dyes where a high value of solution $\mathrm{pH}$ is more suitable, whereas for anionic dye adsorption, a low value of solution $\mathrm{pH}$ is preferred. For the effect of initial dye concentration, because of increased interactions between dye molecules and adsorbent surface, the efficiency of dye removal will increase with an increase in the initial dye concentration, but with a further increase in initial dye, the concentration efficiency of dye removal will decrease due to saturation of the adsorption sites on the surface of the adsorbent. Also, for temperature, if the adsorption process is endothermic, as the temperature increases, the capacity for dye adsorption will increase. If the adsorption process is exothermic, with increasing temperature, the capacity for dye adsorption will decrease. Also, the toxicity of the dyes used in industry should not be neglected while they are removed through the adsorption process. So, it can be concluded that all these factors should be taken into account while the adsorption capacity of various adsorbents is evaluated from an economic point of view.

\section{Conflicts of interest}

There are no conflicts of interest.

\section{Acknowledgements}

The authors M. R. and K. H. would like to thank the Islamic Azad University, Arak Branch and author O. M. would like to thank the Islamic Azad University, Shahre-Qods Branch for their financial support.

\section{References}

1 V. K. Gupta, R. Kumar, A. Nayak, T. A. Saleh and M. A. Barakat, Adv. Colloid Interface Sci., 2013, 24, 193.

2 S. Chatterjee, M. W. Lee and S. H. Woo, Bioresour. Technol., 2010, 101, 1800.

3 A. Ravanpaykar, A. Asfaram and M. R. Fathi emadabadi, J. Chem. Health Risks, 2012, 2, 41.

4 F. Güzel, Ö. Aksoy and G. Akkaya, World Appl. Sci. J., 2012, 20, 965.

5 P. E. Dim, Nat. Appl. Sci., 2013, 3(4), 694.
6 V. K. Gupta, R. Jain, A. Mittal, T. A. Saleh, A. Nayak, S. Agarwal and S. Sikarwar, Mater. Sci. Eng., Proc. Conf., 2012, 32, 12.

7 T. A. Saleh and V. K. Gupta, Environ. Sci. Pollut. Res., 2012, 19, 1224.

8 V. K. Gupta, S. K. Srivastava, D. Mohan and S. Sharma, Waste Manage., 1998, 17, 517.

9 V. K. Gupta, A. Rastogi and A. Nayak, J. Colloid Interface Sci., 2010, 342, 135.

10 A. Mittal, J. Mittal, A. Malviya and V. K. Gupta, J. Colloid Interface Sci., 2009, 340, 16.

11 V. K. Gupta, I. Ali, V. K. Saini, T. Van Gerven, B. D. Van Bruggen and C. Vandecasteele, Ind. Eng. Chem. Res., 2005, 44, 3655.

12 C. Y. Kuo, C. H. Wu and J. Y. Wu, J. Colloid Interface Sci., 2008, 327, 308.

13 B. Royer, N. F. Cardoso, E. C. Lima, J. C. P. Vaghetti, N. M. Simon, T. Calvete and R. C. Veses, J. Hazard. Mater., 2009, 164, 1213.

14 B. H. Hameed, D. K. Mahmoud and A. L. Ahmad, J. Hazard. Mater., 2008, 158, 65.

15 M. M. Ayad and A. A. El-Nasr, J. Nanostruct. Chem., 2012, 3, 3.

16 S. T. Ong, P. S. Keng, S. L. Lee, M. H. Leong and Y. T. Hung, Int. J. Math., Phys. Eng. Sci., 2010, 5, 1270.

17 V. K. Gupta, S. Agarwal and T. A. Saleh, J. Hazard. Mater., 2011, 185, 17.

18 V. K. Gupta, I. Ali, T. A. Saleh, A. Nayak and S. Agarwal, RSC Adv., 2012, 2, 6380.

19 C. Y. Kuo, J. Hazard. Mater., 2008, 152, 949.

20 K. Zare, V. K. Gupta, O. Moradi, et al., J. Nanostruct. Chem., 2015, 5, 227.

21 A. Mittal, J. Mittal, A. Malviya and V. K. Gupta, J. Colloid Interface Sci., 2010, 344, 497.

22 V. K. Gupta, R. Jain, A. Nayak, S. Agarwal and M. Shrivastava, Mater. Sci. Eng., 2011, 31, 1062.

23 V. K. Gupta and A. Nayak, Chem. Eng. J., 2012, 180, 81.

24 T. A. Saleha and V. K. Gupta, J. Colloid Interface Sci., 2012, 371, 101.

25 H. Khani, M. K. Rofouei, P. Arab, V. K. Gupta and Z. Vafaei, J. Hazard. Mater., 2010, 183, 402.

26 O. G. Apul, Q. Wang, Y. Zhou and T. Karanfil, Water Res., 2013, 47, 1648.

27 F. M. Machado, C. P. Bergmann, T. H. M. Fernandes, E. C. Lima, B. Royer, T. Calveteb and S. B. Faganc, J. Hazard. Mater., 2011, 192, 1122.

28 L. Fan, C. Luo, M. Sun, H. Qiu and X. Li, Colloids Surf., B, 2013, 103, 601.

29 F. Najafi, O. Moradi, M. Rajabi, M. Asif, I. Tyagi, S. Agarwal and V. K. Gupta, J. Mol. Liq., 2015, 208, 106.

30 S. Karthikeyana, V. K. Gupta, R. Boopathy, A. Titusa and G. Sekaran, J. Mol. Liq., 2012, 173, 153.

31 A. K. Jain, V. K. Gupta, A. Bhatnagar and Suhas, Sep. Sci. Technol., 2003, 38, 463.

32 V. K. Gupta, A. Nayak and S. Agarwal, Environmental Engineering Research, 2015, 20(1), 1. 
33 T. A. Saleha and V. K. Gupta, Adv. Colloid Interface Sci., 2014, 211, 93.

34 V. K. Gupta, R. Kumar, A. Nayak, T. A. Saleh and M. A. Barakat, Adv. Colloid Interface Sci., 2013, 193-194, 24.

35 R. Saravanan, E. Sacari, F. G. Mohammad, M. Khan, E. Mosquera and V. K. Gupta, J. Mol. Liq., 2016, 221, 1029.

36 A. Mittal, D. Kaur, A. Malviya, J. Mittal and V. K. Gupta, J. Colloid Interface Sci., 2009, 337, 345.

37 V. K. Gupta, A. Mittal, D. Jhare and J. Mittal, RSC Adv., 2012, $2,8381$.

38 V. K. Gupta, A. Mittal, L. Kurup and J. Mittal, J. Colloid Interface Sci., 2006, 304, 52.

39 R. Saravanan, V. K. Gupta, E. Mosquera, F. Gracia, V. Narayanan and A. Stephen, J. Saudi Chem. Soc., 2015, 19, 521.

40 R. Saravanan, M. M. Khan, V. K. Gupta, E. Mosquera, F. Gracia, V. Narayanang and A. Stephen, RSC Adv., 2015, 5, 34645.

41 G. Crini, Bioresour. Technol., 2006, 97, 1061.

42 R. Saravanan, V. K. Gupta, E. Mosquera and F. Gracia, J. Mol. Liq., 2014, 198, 409.

43 R. Saravanan, S. Karthikeyan, V. K. Gupta, G. Sekaran, V. Narayanan and A. Stephen, Mater. Sci. Eng., 2013, 33, 91.

44 R. Saravanan, S. Joicy, V. K. Gupta, V. Narayanan and A. Stephen, Mater. Sci. Eng., 2013, 33, 4725.

45 A. K. Jain and V. K. Gupta, J. Hazard. Mater., 2003, 101, 31. 46 V. K. Gupta, A. Mittal, D. Jhare and J. Mittal, RSC Adv., 2012, $2,8381$.

47 T. A. Saleha and V. K. Gupta, Sep. Purif. Technol., 2012, 89, 245.

48 S. Karthikeyan, V. K. Gupta, R. Boopathy, A. Titus and G. Sekaran, J. Mol. Liq., 2012, 173, 153.

49 T. A. Saleh and V. K. Gupta, Adv. Colloid Interface Sci., 2014, 211, 93.

50 T. A. Saleh and V. K. Gupta, J. Colloid Interface Sci., 2011, 362, 337.

51 M. Yari, M. Rajabi, O. Moradi, A. Yari, M. Asif, S. Agarwal and V. K. Gupta, J. Mol. Liq., 2015, 209, 50-57.

52 B. Enayatpour, M. Rajabi, M. Yari, S. M. R. Mirkhan, F. Najafi, O. Moradi, A. K. Bharti, S. Agarwal and V. K. Gupta, J. Mol. Liq., 2017, 231, 566.

53 F. Najafi and M. Rajabi, Int. Nano Lett., 2015, 5(4), 187.

54 D. Liu, W. Zhao, S. Liu, Q. Cen and Q. Xue, Surf. Coat. Technol., 2016, 286, 354.

55 C. He, L. Sun, C. Zhang, X. Peng, K. Zhang and J. Zhong, Solid State Commun., 2012, 152, 1560.

56 T. Wumair, J. D. Lu, Z. Mingde and C. X. Kang, Ionics, 2013, 19, 1855.

57 F. L. Michael, V. De, S. H. Tawfick, R. H. Baughman and A. J. Hart, Science, 2013, 339, 535.

58 D. Robati, S. Bagheriyan, M. Rajabi, O. Moradi and A. A. Peyghan, Phys. Rev. E, 2016, 83, 1.

59 P. Kanninen, M. Borghei, J. Hakanpää, E. I. Kauppinen, V. Ruiz and T. Kallio, J. Electroanal. Chem., 2017, 793, 48.

60 M. Rezaei-Sameti and E. Samadi Jamil, J. Nanostruct. Chem., 2016, 6, 197.
61 S. B. Fagan, A. G. S. Filho, J. O. G. Lima, J. M. Filho, O. P. Ferreira, I. O. Mazali, O. L. Alves and M. S. Dresselhaus, Nano Lett., 2004, 4, 1285.

62 M. Rajabi, O. Moradi and A. Mazlomifar, Int. J. Nano Dimens., 2015, 6, 227.

63 M. T. Yagub, T. K. Sen, S. Afroze and H. M. Ang, Adv. Colloid Interface Sci., 2014, 209, 172.

64 V. K. Gupta, J. Environ. Manage., 2009, 90, 2313.

65 M. J. Ahmeda, J. Environ. Chem. Eng., 2016, 4, 89.

66 K. Hunger, Industrial Dyes: Chemistry, Properties, Applications, Wiley-VCH, 2007.

67 T. W. Seow and C. K. Lim, Int. J. Appl. Eng. Res., 2016, 11, 2675.

68 D. Robati, B. Mirza, M. Rajabi, O. Moradi, I. Tyagi, S. Agarwal and V. K. Gupta, Chem. Eng. J., 2016, 284, 687.

69 V. K. Gupta, I. Ali, Suhas and D. Mohan, J. Colloid Interface Sci., 2003, 265, 257.

70 R. Liu, B. Zhang, D. Mei, H. Zhang and J. Liu, Desalination, 2011, 268, 111.

71 D. Robati, S. Bagheriyan and M. Rajabi, Int. Nano Lett., 2015, 5(3), 179.

72 Y. Qi, M. Yang, W. Xu, S. He and Y. Men, J. Colloid Interface Sci., 2017, 486, 84.

73 A. Ozcan, E. M. Oncu and A. S. Ozcan, J. Hazard. Mater., 2006, 129, 244.

74 M. Rajabi, B. Mirza, K. Mahanpoor, M. Mirjalili, F. Najafi, O. Moradi, H. Sadegh, R. Shahryari-ghoshekandi, M. Asif, I. Tyagi, S. Agarwalk and V. K. Gupta, J. Ind. Eng. Chem., 2016, 34, 130.

75 G. M. S. ElShafei, I. M. A. ElSherbiny, A. S. Darwish and C. A. Philip, Chem. Eng. Res. Des., 2014, 92, 461.

76 D. Robati, S. Bagheriyan, M. Rajabi, O. Moradi and A. A. Peyghan, Phys. Rev. E, 2016, 83, 1.

77 J. G. Yu, X. H. Zhao, H. Yang, X. H. Chen, Q. Yang, L. Y. Yu, J. H. Jiang and X. Q. Chen, Sci. Total Environ., 2014, 482, 241.

78 H. Khani and O. Moradi, J. Nanostruct. Chem., 2013, 3, 73.

79 L. Tian, J. Zhang, H. Shi, N. Li and Q. Ping, J. Dispersion Sci. Technol., 2016, 37, 1059.

80 B. A. Fil, Part. Sci. Technol., 2016, 34, 118.

81 J. Zhang, M. Liu, Z. Liu, T. Yang, Q. He, K. Yang and H. Wang, J. Sol-Gel Sci. Technol., 2017, 82, 424.

82 D. Robati, B. Mirza, R. Ghazisaeidi, M. Rajabi, O. Moradi, I. Tyagi, S. Agarwal and V. K. Gupta, J. Mol. Liq., 2016, 216, 830 .

83 D. M. Ruthven, Principles of Adsorption and Adsorption Processes, J. Wiley \& Sons, New York, 1984.

84 T. W. Seow and C. K. Lim, Int. J. Appl. Eng. Res., 2016, 11, 2675.

85 D. Robati, M. Rajabi, O. Moradi, F. Najafi, I. Tyagi, S. Agarwal and V. K. Gupta, J. Mol. Liq., 2016, 214, 259.

86 C. Y. Kuo, C. H. Wu and J. Y. Wu, J. Colloid Interface Sci., 2008, 327, 308.

87 W. Konicki, I. Pełech, E. Mijowska and I. Jasińska, Clean: Soil, Air, Water, 2014, 42, 284.

88 Y. Yao, F. Xu, M. Chen, Z. Xu and Z. Zhu, Bioresour. Technol., 2010, 101, 3040. 
89 R. M. Tinnacher, M. Holmboe, C. Tournassat, I. C. Bourg and J. A. Davis, Geochim. Cosmochim. Acta, 2016, 177, 130.

90 G. Vilardi, L. D. Palma and N. Verdone, Chin. J. Chem. Eng., 2017, DOI: 10.1016/j.cjche.2017.06.026.

91 A. Jain, R. Balasubramanian and M. P. Srinivasan, Chem. Eng. J., 2015, 273, 622.

92 R. Ben-Mansour, M. A. Habib, O. E. Bamidele, M. Basha, N. A. A. Qasem, A. Peedikakkal, T. Laoui and M. Ali, Appl. Energy, 2016, 161, 225.

93 L. A. Lane, X. Qian, A. M. Smith and S. Nie, Annu. Rev. Phys. Chem., 2015, 66, 521.

94 D. M. Ruthven, S. Farooq and K. S. Knaebel, Pressure Swing Adsorption, VCH, New York, 1994.

95 M. Rajabi, O. Moradi and K. Zare, Int. Nano Lett., 2017, 7, 35.

96 H. Li, D. Xiao, H. He, R. Lin and P. Zuo, Met. Soc. China, 2013, 23, 2657.

97 M. Yari, M. Norouzi, A. H. Mahvi, M. Rajabi, A. Yari, O. Moradi, I. Tyagi and V. K. Gupta, Desalin. Water Treat., 2016, 57, 11195.

98 M. Shirmardi, A. H. Mahvi, B. Hashemzadeh, A. Naeimabadi, G. Hassani and M. Vosoughi Niri, Korean J. Chem. Eng., 2013, 30, 1603.

99 Y. Zeng, L. Zhao, W. Wu, G. Lu, F. Xu, Y. Tong, W. Liu and J. Du, J. Appl. Polym. Sci., 2013, 127, 2475.

100 G. Daneshvar Tarigh, F. Shemirani and N. Seif Maz'haric, RSC Adv., 2015, 5, 35070.

101 M. Setareh Derakhshan and O. Moradi, J. Ind. Eng. Chem., 2014, 20, 3186.

102 O. Kerkez and Ş. S. Bayazit, J. Nanopart. Res., 2014, 16, 24.

103 Z. Shahryari, A. Soltani Goharrizi and M. Azadi, Int. J. Water Resour. Environ. Eng., 2010, 2, 016.

104 W. A. Khanday, F. Marrakchi, M. Asif and B. H. Hameed, J. Taiwan Inst. Chem. Eng., 2017, 70, 32.

105 O. Moradi, Fullerenes, Nanotubes, Carbon Nanostruct., 2013, 21, 286.

106 A. F. Alkaim, Z. Sadik, D. K. Mahdi, S. M. Alshrefi, A. M. AlSammarraie, F. M. Alamgir, P. M. Singh and A. M. Aljeboree, Korean J. Chem. Eng., 2015, 32, 2456.

107 A. Ahmad, M. H. Razali, M. Mamat, F. S. B. Mehamod and K. A. M. Amin, Chemosphere, 2017, 168, 474.

108 Y. Yao, B. He, F. Xu and X. Chen, Chem. Eng. J., 2011, 170, 82.
109 J. Ma, F. Yu, L. Zhou, L. Jin, M. Yang, J. Luan, Y. Tang, H. Fan, Z. Yuan and J. Chen, ACS Appl. Mater. Interfaces, 2012, 4, 5749.

110 H. Y. Zhu, R. Jiang, L. Xiao and G. M. Zeng, Bioresour. Technol., 2010, 101, 5063.

111 M. Omaish Ansari, R. Kumar, S. A. Ansari, S. P. Ansari, M. A. Barakat, A. Alshahrie and M. H. Cho, J. Colloid Interface Sci., 2017, 496(15), 407.

112 S. Yang, L. Wang, X. Zhang, W. Yang and G. Song, Chem. Eng. J., 2015, 275, 315.

113 A. K. Mishra, T. Arockiadoss and S. Ramaprabhu, Chem. Eng. J., 2010, 162, 1026.

114 K. Zare, H. Sadegh, R. Shahryari-ghoshekandi, B. Maazinejad, V. Ali, I. Tyagi, S. Agarwal and V. K. Gupta, J. Mol. Liq., 2015, 212, 266.

115 F. M. Machado, C. P. Bergmann, E. C. Lima, M. A. Adebayo and S. B. Fagan, Mater. Res., 2014, 17, 153.

116 F. M. Machado, C. P. Bergmann, E. C. Lima, B. Royer, F. E. de Souza, I. M. Jauris, T. Calvete and S. B. Fagan, Phys. Chem. Chem. Phys., 2012, 14, 11139.

117 E. Bazrafshan, F. Kord Mostafapour, S. Rahdar and A. H. Mahvi, Desalin. Water Treat., 2015, 54, 2241.

118 F. M. Machado, C. P. Bergmann, T. H. M. Fernandes, E. C. Lima, B. Royer, T. Calvete and S. B. Fagan, J. Hazard. Mater., 2011, 192, 1122.

119 C. H. Wu, J. Hazard. Mater., 2007, 144, 93.

120 W. Konicki, I. Pełech, E. Mijowska and I. Jasinska, Chem. Eng. J., 2012, 210, 87.

121 L. D. T. Prola, F. M. Machado, C. P. Bergmann, F. E. de Souza, C. R. Gally, E. C. Lima, M. A. Adebayo, S. L. P. Dias and T. Calvete, J. Environ. Manage., 2013, 130, 166.

122 M. Shirmardi, A. Mesdaghinia, A. H. Mahavi, S. Nasseri and R. Nabizadeh, Eur. J. Chem., 2012, 9, 2371.

123 F. Geyikçi, Fullerenes, Nanotubes, Carbon Nanostruct., 2013, 21, 579.

124 R. S. Ruoff and D. C. Lorents, Carbon, 1995, 33, 925.

125 J. P. Lu, Phys. Rev. Lett., 1997, 79, 1297.

126 J. P. Salvetat, J. M. Bonard, N. H. Thomson, A. J. Kulik, L. Forró, W. Benoit and L. Zuppiroli, Appl. Phys. A, 1999, 69, 255.

127 J. Chen, M. A. Hamon, H. Hu, Y. Chen, A. M. Rao, P. C. Eklund and R. C. Haddon, Science, 1998, 282, 95.

128 M. Ohnishi, T. Shiga and J. Shiomi, Phys. Rev. B, 2017, 95, 155. 